OPEN ACCESS

Edited by:

Kenneth K.Y. Wong

The University of Hong Kong,

Hong Kong

Reviewed by:

Akihiro Yoneda,

Osaka City General Hospital, Japan

Marilyn West Butler,

Oregon Health and Science University,

United States

*Correspondence:

Jinshi Huang

jsdr2002@126.com

Specialty section:

This article was submitted to

Pediatric Surgery,

a section of the journal

Frontiers in Pediatrics

Received: 25 June 2020 Accepted: 31 August 2020 Published: 02 October 2020

Citation:

Yang S, Cai S, Liao J, Peng X and

Huang J (2020) Risk Factors and

Reasons for Discharge Against Medical Advice for Newborns With

Neonatal Surgical Diseases: A Preliminary Study From a Tertiary Care

Hospital in Beijing, China.

Front. Pediatr. 8:576270

doi: 10.3389/fped.2020.576270

\section{Risk Factors and Reasons for} Discharge Against Medical Advice for Newborns With Neonatal Surgical Diseases: A Preliminary Study From a Tertiary Care Hospital in Beijing, China

\author{
Shen Yang ${ }^{1}$, Siyu Cai ${ }^{2}$, Junmin Liao ${ }^{1}$, Xiaoxia Peng $^{2}$ and Jinshi Huang ${ }^{1 *}$ \\ 'Department of Neonatal Surgery, Beijing Children's Hospital, Capital Medical University, National Center for Children's \\ Health, Beijing, China, ${ }^{2}$ Center for Clinical Epidemiology and Evidence-Based Medicine, Beijing Children's Hospital, Capital \\ Medical University, National Center for Children's Health, Beijing, China
}

Background: To identify the risk factors and reasons for discharge against medical advice (DAMA) for newborns with neonatal surgical diseases in a tertiary care hospital in China.

Methods: A retrospective study was conducted on all newborn patients admitted to the neonatal surgery department of Beijing Children's Hospital between January 1, 2016 and January 1, 2020. Medical records were compared between DAMA and non-DAMA patients. Univariate and multivariate logistic regression analyses were conducted to identify potentially useful characteristics for predicting DAMA.

Results: During the study period, 854 newborns were admitted to the neonatal surgery department. A total of 68 DAMA patients (68/854, 7.96\%, 47 boys), with a median age at diagnosis of 1 day (range, from birth to 21 days), were included in this study. After multivariate analysis, we found that emergency admission, age at admission $\leq 5$ days, rejection for surgery, and admission to the neonatal intensive care unit were significant independent risk factors for DAMA. According to the electronic medical records, the reasons for DAMA included belief in incurability and concerns about the prognosis of the disease $(n=31)$, multiple malformations with poor prognosis $(n=8)$, severe postoperative complications $(n=5)$, financial difficulties $(n=3)$, refusal of further examinations $(n=2)$, assumption of clinical improvement $(n=1)$, and unknown $(n=18)$.

Conclusions: This preliminary study showed that neonatal surgical patients in critical conditions were high-risk groups for DAMA, and the main possible reasons for DAMA were the parents' belief in incurability and concerns about the prognosis of the disease.

Keywords: discharge against medical advice (DAMA), newborns, neonatal surgical diseases, risk factors, reasons 


\section{INTRODUCTION}

The neonatal period, a child's 1st month of life, is the most critical time for survival. Congenital malformations, preterm birth, neonatal sepsis, and injury remain leading causes of death (1). Congenital malformations, the most common neonatal surgical diseases, are a leading cause of mortality and morbidity in the neonatal period and infancy besides labor associated problems like asphyxia and prematurity (2). Approximately $2.5-5 \%$ of all neonates have at least one anatomical malformation (3), but the spectrum of this heterogeneous group of diseases is very wide.

In the department of neonatal surgery in developing countries, some parents of newborns with neonatal surgical diseases (especially congenital malformations) will choose to discharge against medical advice (DAMA) before or after the surgery. Possible reasons include the critical condition of the newborn, the combination of multiple malformations, family socio-economic factors, and concerns about the prognosis of the disease.

DAMA may lead to the worsening conditions or death of patients and increase the risk of readmission. Many studies focus on the abandonment of treatment and DAMA for children's cancer, and analyze the risk factors (4-6). However, few studies focus on DAMA for neonatal surgical diseases. This preliminary study aims to explore the relevant factors and reasons of DAMA by reviewing neonatal medical records from the department of neonatal surgery in our center.

\section{METHODS}

\section{Patients and Clinical Characteristics}

We retrospectively collected the medical records of all newborn patients (28 days of age or younger) admitted to the neonatal surgery department of Beijing Children's Hospital between January 1, 2016 and January 1, 2020. Data on gender, age at admission, birth weight, gestational age, mode of delivery, father's, and mother's age at child's birth, gravidity and parity, geographic location, urgency of admission (patients with diseases such as congenital anorectal malformations, esophageal atresia, intestinal atresia, and abdominal wall deformity, as well as patients with gastrointestinal perforation, intestinal obstruction, bleeding, dehydration, acute infection and other complications, were usually admitted from the emergency department), admission condition, diagnosis, treatment of surgery and operative time, re-operation during the first hospitalization, admission to the neonatal intensive care unit (indications included premature and low birth weight infants, patients requiring mechanical ventilation, patients after cardiopulmonary resuscitation, and so on), length of stay, hospitalization expense, and readmission were collected. Other information was also collected for DAMA patients, including the condition of siblings, whether multiple malformations, congenital heart disease, chromosome abnormality, or VACTERL syndrome were present, and the reasons for DAMA. All methods were carried out in accordance with relevant guidelines and regulations, and the study was approved by the Medical Ethics Committee of Beijing Children's Hospital (2020-Z-039). A waiver of consent was provided for the analyses conducted in this study.

\section{Statistical Analysis}

Statistical analysis was performed by SAS 9.4. Continuous variables were presented as the mean and standard deviation for normal distribution, or median and interquartile range for non-normal distribution. Categorical variables were reported as counts and percentages. Two independent samples $t$-tests and $\chi^{2}$ tests were used to compare characteristics between the DAMA and non-DAMA groups. Receiver operating characteristic (ROC) curve analysis was performed to determine the most appropriate cut-off values. Univariate and multivariate logistic regression analyses were conducted to select potentially useful characteristics for predicting DAMA. $P<0.05$ was considered statistically significant.

\section{RESULTS}

\section{Comparison Between DAMA and Non-DAMA Groups}

During the study period from January 2016 to December 2019, 854 newborn patients (28 days of age or younger) were admitted to the neonatal surgery department of Beijing Children's Hospital. A total of 68 DAMA patients (68/854, 7.96\%, 47 boys and 21 girls), with a median age at diagnosis of 1 day (range, from birth to 21 days), were included in this study. As shown in Table 1, by comparing medical records between DAMA $(n=68)$ and non-DAMA $(n=786)$ patients, we found significant differences in age at admission, birth weight, urgency of admission, admission condition, treatment of surgery, admission of neonatal intensive care unit, length of stay, and hospitalization expense (all $P<0.05$ ). However, there were no differences in gender, gestational age, mode of delivery, father's, and mother's age at child's birth, parity and gravidity, geographic location, re-operation during the first hospitalization, operative time, and readmission between the two groups (all $P>0.05$ ). The disease distribution of the two groups is shown in Table 2.

\section{Risk Factors for DAMA}

In order to find the risk factors for DAMA, we further conducted a multivariate analysis. ROC curve analysis was used to determine the stratification value for age at admission and birth weight according to the maximum combined sensitivity and specificity values. The cut-off values for the above characteristics were 5 days and 3,000 g, respectively (Supplementary Figure 1). As shown in Table 3, multivariate analysis showed that emergency admission, age at admission $\leq 5$ days, rejection for surgery, and admission to the neonatal intensive care unit were significant independent risk factors for DAMA.

\section{Clinical Characteristics of DAMA Patients}

As shown in Table 4, among the 68 DAMA neonates, 4 were twins, 28 had an older sibling (one older sibling had died of severe congenital malformation after birth and another died of intracerebral hemorrhage after birth), 30 had multiple malformations, 13 had congenital heart disease, 5 had chromosome abnormalities, and 5 had VACTERL syndrome. According to the electronic medical records, the reasons for 68 DAMA newborns included belief in incurability and 
TABLE 1 | Comparison between DAMA and non-DAMA groups.

\begin{tabular}{|c|c|c|c|c|c|}
\hline Variables & & DAMA $(n=68)$ & Non-DAMA $(n=786)$ & Results & $p$ \\
\hline \multirow[t]{2}{*}{ Gender ( $n, \%)$} & Boy & $47(69.12)$ & $499(63.49)$ & 0.8610 & 0.3535 \\
\hline & Girl & $21(30.88)$ & $287(36.51)$ & & \\
\hline Age at admission (median, days) & & $1.00(1.00,3.00)$ & $3.00(1.00,15.00)$ & -4.6987 & $<0.0001$ \\
\hline Birth weight (median, g) & & $2,955.00(2,562.50,3,400.00)$ & $3,240.00(2,900.00,3,590.00)$ & -3.2593 & 0.0011 \\
\hline \multirow[t]{2}{*}{ Gestational age ( $n, \%)$} & Preterm & $9(13.24)$ & $85(12.28)$ & 0.052 & 0.8200 \\
\hline & Term & $59(86.76)$ & 607 (87.72) & & \\
\hline \multirow[t]{2}{*}{ Mode of delivery ( $n, \%)$} & Cesarean delivery & $38(55.88)$ & $336(48.55)$ & 1.3300 & 0.2488 \\
\hline & Spontaneous vaginal delivery & $30(44.12)$ & $356(51.45)$ & & \\
\hline Father's age at child's birth (median, years) & & $30(27,34)$ & $31(28,34)$ & -1.5955 & 0.1106 \\
\hline Mother's age at child's birth (median, years) & & $29(27,32)$ & $30(27,33)$ & -1.0713 & 0.2840 \\
\hline Gravidity (median) & & $2(1,3)$ & $2(1,2)$ & 0.8923 & 0.3722 \\
\hline Parity (median) & & $1(1,2)$ & $2(1,2)$ & -1.3663 & 0.1719 \\
\hline \multirow[t]{2}{*}{ Geographic location (n, \%) } & City & $40(58.82)$ & $423(53.82)$ & 0.6320 & 0.4266 \\
\hline & Village & $28(41.18)$ & $363(46.18)$ & & \\
\hline \multirow[t]{2}{*}{ Urgency of admission ( $n, \%)$} & Emergency & $55(80.88)$ & $442(56.23)$ & 15.6290 & $<0.0001$ \\
\hline & Planned & $13(19.12)$ & $344(43.77)$ & & \\
\hline \multirow[t]{2}{*}{ Admission condition ( $n, \%)$} & Critical & $50(74.63)$ & $405(51.59)$ & 13.1630 & 0.0003 \\
\hline & Stable & $17(25.37)$ & $380(48.41)$ & & \\
\hline \multirow[t]{2}{*}{ Surgery $(n, \%)$} & No & $25(36.76)$ & $59(7.51)$ & 60.4110 & $<0.0001$ \\
\hline & Yes & $43(63.24)$ & 727 (92.49) & & \\
\hline \multirow{2}{*}{ Re-operation during the first hospitalization $(n, \%)$} & No & 67 (98.53) & 769 (97.84) & 0.1450 & 0.7030 \\
\hline & Yes & $1(1.47)$ & $17(2.16)$ & & \\
\hline Operative time (median, min) & & $75.00(52.75,117.25)$ & $68.00(48.00,95.00)$ & 1.4996 & 0.1337 \\
\hline \multirow[t]{2}{*}{ Neonatal intensive care unit $(n, \%)$} & No & $52(76.47)$ & 704 (89.57) & 10.5680 & 0.0012 \\
\hline & Yes & 16 (23.53) & $82(10.43)$ & & \\
\hline Length of stay (median, days) & & $3.50(1.00,14.00)$ & $13.00(8.00,19.00)$ & -5.9985 & $<0.0001$ \\
\hline Hospitalization expense (median, CNY) & & $12654.03(3857.53,33802.47)$ & $21840.18(15272.80,29655.49)$ & -3.9819 & $<0.0001$ \\
\hline \multirow[t]{2}{*}{ Readmission } & No & $59(86.76)$ & $665(84.61)$ & 0.2260 & 0.6344 \\
\hline & Yes & $9(13.24)$ & $121(15.39)$ & & \\
\hline
\end{tabular}

TABLE 2 | The disease distribution of the DAMA and non-DAMA groups.

\begin{tabular}{|c|c|c|c|c|}
\hline \multirow[t]{2}{*}{ Discharge diagnosis } & \multicolumn{2}{|c|}{ DAMA $(n=68)$} & \multicolumn{2}{|c|}{ Non-DAMA $(n=786)$} \\
\hline & Yes $(n, \%)$ & No $(n, \%)$ & Yes $(n, \%)$ & No $(n, \%)$ \\
\hline Congenital anorectal malformation & $17(25.00)$ & $51(75.00)$ & $166(21.12)$ & $620(78.88)$ \\
\hline Esophageal atresia/tracheoesophageal fistula & $13(19.12)$ & $55(80.88)$ & $34(4.33)$ & $752(95.67)$ \\
\hline Congenital intestinal atresia & $11(16.18)$ & $57(83.82)$ & $66(8.40)$ & $720(91.60)$ \\
\hline Hirschsprung's disease/Hirschsprung's allied disease & $10(14.71)$ & $58(85.29)$ & $105(13.36)$ & $681(86.64)$ \\
\hline Congenital duodenal obstruction & $3(4.41)$ & 65 (95.59) & $75(9.54)$ & $711(90.46)$ \\
\hline Congenital malrotation of the intestine & $3(4.41)$ & 65 (95.59) & $58(7.38)$ & $728(92.62)$ \\
\hline Tumor & $2(2.94)$ & $66(97.06)$ & $80(10.18)$ & $706(89.82)$ \\
\hline Intestinal obstruction, perforation of digestive tract, peritonitis & $2(2.94)$ & $66(97.06)$ & $50(6.36)$ & $736(93.64)$ \\
\hline Congenital abdominal wall malformation & $2(2.94)$ & $66(97.06)$ & $36(4.58)$ & $750(95.42)$ \\
\hline Encephalocele and meningocele & $2(2.94)$ & $66(97.06)$ & $5(0.64)$ & 781 (99.36) \\
\hline Congenital hypertrophic pyloric stenosis & $0(0)$ & $68(100.00)$ & $50(6.36)$ & $736(93.64)$ \\
\hline Congenital bile duct malformation & $0(0)$ & $68(100.00)$ & $8(1.02)$ & $778(98.98)$ \\
\hline Necrotic enterocolitis of newborn & $0(0)$ & $68(100.00)$ & $5(0.64)$ & 781 (99.36) \\
\hline Congenital diaphragmatic hernia & $0(0)$ & $68(100.00)$ & $4(0.51)$ & $782(99.49)$ \\
\hline Others & $3(4.41)$ & 65 (95.59) & $44(5.60)$ & $742(94.40)$ \\
\hline
\end{tabular}


TABLE 3 | Multivariate logistic regression analysis of prediction of DAMA.

\begin{tabular}{|c|c|c|c|c|c|}
\hline Variables & Estimate & $\begin{array}{l}\text { Standard } \\
\text { Error }\end{array}$ & Wald & $\boldsymbol{P}$ & OR \\
\hline Emergency admission & 0.7943 & 0.3394 & 5.4791 & 0.0192 & $\begin{array}{c}2.213 \\
(1.138,4.304)\end{array}$ \\
\hline $\begin{array}{l}\text { Age at admission } \leq 5 \\
\text { days }\end{array}$ & 1.3284 & 0.3862 & 11.8335 & 0.0006 & $\begin{array}{c}3.775 \\
(1.771,8.047)\end{array}$ \\
\hline Rejection for surgery & 2.3946 & 0.3249 & 54.3264 & $<0.0001$ & $\begin{array}{c}0.091 \\
(0.048,0.172)\end{array}$ \\
\hline $\begin{array}{l}\text { Admission to the } \\
\text { neonatal intensive } \\
\text { care unit }\end{array}$ & 1.1271 & 0.3431 & 10.7932 & 0.0010 & $\begin{array}{c}3.087 \\
(1.576,6.046)\end{array}$ \\
\hline
\end{tabular}

TABLE 4 | The clinical characteristics of the DAMA patients.

\begin{tabular}{|c|c|c|c|}
\hline \multirow[t]{2}{*}{ Variables } & & \multicolumn{2}{|c|}{ Number $(n=68)$} \\
\hline & & Yes $(n, \%)$ & No $(n, \%)$ \\
\hline Twin & & $4(5.88)$ & $64(94.12)$ \\
\hline Elder brother or sister & & 28 * $(41.18)$ & $40(58.82)$ \\
\hline $\begin{array}{l}\text { Multiple } \\
\text { malformations }\end{array}$ & & $30(44.12)$ & $38(55.88)$ \\
\hline $\begin{array}{l}\text { Congenital heart } \\
\text { disease }\end{array}$ & & $13(19.12)$ & $55(80.88)$ \\
\hline $\begin{array}{l}\text { Chromosome } \\
\text { abnormality }\end{array}$ & & $5(7.35)$ & $63(92.65)$ \\
\hline VACTERL syndrome & & $5(7.35)$ & $63(92.65)$ \\
\hline \multirow[t]{7}{*}{ Reasons for DAMA } & $\begin{array}{l}\text { Belief in incurability and } \\
\text { concerns about the } \\
\text { prognosis of the } \\
\text { diseases }\end{array}$ & $31(45.59)$ & $37(54.41)$ \\
\hline & $\begin{array}{l}\text { Multiple malformations } \\
\text { with poor prognosis }\end{array}$ & $8(11.76)$ & $60(88.24)$ \\
\hline & $\begin{array}{l}\text { Severe postoperative } \\
\text { complications }\end{array}$ & $5(7.35)$ & $63(92.65)$ \\
\hline & Financial difficulties & $3(4.41)$ & $65(95.59)$ \\
\hline & $\begin{array}{l}\text { Refusal of further } \\
\text { examinations }\end{array}$ & $2(2.94)$ & 66 (97.06) \\
\hline & $\begin{array}{l}\text { Assumption of clinical } \\
\text { improvement }\end{array}$ & $1(1.47)$ & $67(98.53)$ \\
\hline & Unknown & $18(26.47)$ & $50(73.53)$ \\
\hline
\end{tabular}

*One older sibling had died of severe congenital malformation after birth and another died of intracerebral hemorrhage after birth.

concerns about the prognosis of the diseases $(n=31)$, multiple malformations with poor prognosis $(n=8)$, severe postoperative complications $(n=5)$, financial difficulties $(n=$ 3 ), refusal of further examinations $(n=2)$, assumption of clinical improvement $(n=1)$, and unknown $(n=18)$.

\section{DISCUSSION}

As far as we know, this is the first study to explore the risk factors and reasons for DAMA newborns with neonatal surgical diseases. This preliminary study showed that neonatal surgical patients in critical conditions (emergency admission, age at admission $\leq 5$ days, rejection for surgery, and admission to the neonatal intensive care unit) were high-risk groups for DAMA, and the main possible reasons for DAMA were the parents' belief in incurability and concerns about their respective prognosis, and multiple malformations with poor prognosis.

DAMA is a matter of grave concern and a challenge routinely faced by hospital treatment teams. Patients who leave medical facilities before their treatment is completed and against doctors' approval tend to deteriorate. However, these incidents are difficult to eliminate and is prevalent in almost all healthcare facilities, leading to unpredictable complications (7). DAMA rates vary across countries, age groups, diseases, and hospital departments. Among neonates, previous studies have reported that the proportion of DAMA is between 1.6 and $25.4 \%$ (810). First week of life, low socioeconomic class and education of parents have been reported as risk factors of newborns who subsequently DAMA (9). Common reasons identified for DAMA among children in former studies included parents' false perception that their child's condition had improved; difficulties arranging care for the patient's siblings at home; perception of poor clinical outcome; logistical reasons such as living far from the hospital, or parents living outside the province; unavailability of consultation appointment; dissatisfaction with treatment; discomfort caused by frequent blood tests for laboratory investigations; child's refusal to stay at the hospital; prolonged hospitalization period causing financial problems, inconvenience (lost work days), and preference for traditional healers (7-9). However, in our study, the main reasons for DAMA were belief in incurability and concerns about the prognosis of the diseases, and multiple malformations with poor prognosis.

Parents of pediatric patients are faced with a different challenge when opting for DAMA, since patients of this particular age group have neither the required emotional and cognitive maturity nor the legal rights to decide for themselves. Former studies showed that the leading diagnoses in cases of neonatal DAMA were sepsis, asphyxia, prematurity, and jaundice $(8,9)$. These diagnoses have also been identified by WHO as the greatest cause of mortality of newborns in the developing world. However, the top three causes of DAMA in this study were congenital anorectal malformations, esophageal atresia/tracheoesophageal fistula, and congenital intestinal atresia. On the one hand, these diseases are usually accompanied by a variety of other malformations, such as congenital heart disease, urogenital system malformation, spinal deformity, etc., and patients often need to undergo multiple operations. On the other hand, these diseases are associated with a relatively high incidence of short-term and long-term complications after surgery which can also seriously affect the quality of life. Examples include fecal and urinary incontinence and sexual inadequacy after repair of high-type anorectal malformation (11), anastomotic stricture, long-term gastrointestinal, and respiratory complications and comorbidities after repair of long gap esophageal atresia (12), and short bowel syndrome after repair multiple intestinal atresia (13). When parents comprehend the course of treatment and the long-term prognosis of the diseases, many parents state that they cannot tolerate the repeated surgical procedures and the 
uncertain therapeutic effects, especially when the newborn is burdened with multiple malformations.

Socio-economic status of parents is considered one of the major factors related to DAMA in most of the studies conducted on self-discharged neonates. Former studies showed that 54.8$72.1 \%$ parents who self-discharged their child had a lower socioeconomic status (9). However, our study was unable to obtain the relevant socio-economic data of the patients from the medical records. Although no statistical difference was found between the geographic location of city or village between the DAMA and non-DAMA groups, many parents did choose to self-discharge their babies due to financial difficulties in our study. In order to solve the problem of children who come from financially unstable families being unable to get medical treatment, China has been vigorously implementing medical insurance policies in urban and rural areas for many years. In addition, China implemented a program to assist pediatric patients with congenital structural abnormalities in 2017 , and by 2020 , more than 15,000 patients nationwide have benefited.

Previous studies have shown that the readmission rate of DAMA patients is significantly higher than non-DAMA patients (8). This phenomenon was not found in our study and a possible reason could be that most parents of DAMA newborns chose to refuse treatment. The Hippocratic oath binds a physician to uphold the patients' well-being. However, pediatricians can sometimes be conflicted between deciding on the best clinical course for the child and the parents' decision to discharge their child. Each healthcare professional can play a vital role in preventing DAMA. A good starting point would be the administration of proper DAMA case documentation whereby the underlying reason for DAMA be clearly recorded. This documentation may then be used for legal purposes, and should also be used for potential interventions aimed at reducing DAMA. Additionally, more effective communication and counseling are required between parents and the pediatricians. This may help avoid DAMA and prevent potential damages to the children's health.

Despite the enormous clinical, economic, ethical, and medicolegal implications of DAMA especially in developing countries, it has largely remained an under researched area, particularly in neonates. Limitation of the present study was inability to follow up on DAMA babies to determine their outcome. Detailed DAMA information could not be obtained because a DAMA registry has not yet been established in our hospital. Moreover, the reasons of DAMA may vary according to specific diseases.

\section{REFERENCES}

1. Abbas R, Irfan Waheed KA, Waqar T, Anwar M, Gul R, Hayat S, et al. Reasons of self-discharge from nursery of a tertiary care hospital. J Ayub Med Coll Abbottabad. (2017) 29:658-61.

2. Al-Mohammadi E. Pediatric discharge against medical advice. Int $J$ Health Care Qual Assur. (2019) 32:366-74. doi: 10.1108/IJHCQA-02-2018-0032

3. Al-Turkistani HK. Discharge against medical advice from Neonatal Intensive Care Unit: 10 years experience at a University Hospital. J Family Community Med. (2013) 20:113-5. doi: 10.4103/2230-8229.114774
Within a particular disease, differing development of economy and medical levels will naturally affect the parents' level of understanding of the disease, thereby also affecting the reasons for DAMA. Therefore, based on this preliminary study, we plan to facilitate qualitative research in the future to gain an in-depth understanding of the causes of DAMA newborns with neonatal surgical diseases, and further formulate corresponding policies to minimize the occurrence of DAMA.

In conclusion, this study provides us with a better understanding of the risk factors and reasons for DAMA newborns with neonatal surgical diseases. Understanding these factors can encourage appropriate interventions and policies for reducing DAMA rates in the future. In this way, pediatric patients can be protected from the unfortunate consequences of inappropriate discharge.

\section{DATA AVAILABILITY STATEMENT}

The original contributions presented in the study are included in the article/Supplementary Material, further inquiries can be directed to the corresponding author/s.

\section{ETHICS STATEMENT}

The studies involving human participants were reviewed and approved by Medical Ethics Committee of Beijing Children's Hospital (2020-Z-039). Written informed consent from the participants' legal guardian/next of kin was not required to participate in this study in accordance with the national legislation and the institutional requirements.

\section{AUTHOR CONTRIBUTIONS}

Study conception and design: JH and SY. Data acquisition: JL. Analysis and data interpretation: SC and XP. Drafting of the manuscript: SY. Contributed to the article and approved the submitted version: All authors.

\section{SUPPLEMENTARY MATERIAL}

The Supplementary Material for this article can be found online at: https://www.frontiersin.org/articles/10.3389/fped. 2020.576270/full\#supplementary-material

Supplementary Figure $1 \mid R O C$ curve analyses. Stratification values for (A) age at admission and (B) birth weight, which were calculated by ROC curve analyses.
4. Cai J, Yu J, Zhu X, Hu S, Zhu Y, Jiang $H$, et al. Treatment abandonment in childhood acute lymphoblastic leukaemia in China: a retrospective cohort study of the Chinese Children's Cancer Group. Arch Dis Child. (2019) 104:522-9. doi: 10.1136/archdischild-2018316181

5. Calzolari E, Barisic I, Loane M, Morris J, Wellesley D, Dolk H, et al. Epidemiology of multiple congenital anomalies in Europe: a EUROCAT population-based registry study. Birth Defects Res A Clin Mol Teratol. (2014) 100:270-6. doi: 10.1002/bdra. 23240 
6. Devpura B, Bhadesia P, Nimbalkar S, Desai S, Phatak A. Discharge against medical advice at neonatal intensive care unit in Gujarat, India. Int J Pediatr. (2016) 2016:1897039. doi: 10.1155/2016/1897039

7. Fischer RT, Friend B, Talmon GA, Grant WJ, Quiros-Tejeira RE, Langnas $\mathrm{AN}$, et al. Intestinal transplantation in children with multiple intestinal atresias and immunodeficiency. Pediatr Transplant. (2014) 18:190-6. doi: $10.1111 /$ petr. 12211

8. Hong D, Zhou C, He H, Wang Y, Lu J, Hu S. A 10-year followup survey of treatment abandonment of children with acute myeloid leukemia in Suzhou, China. J Pediatr Hematol Oncol. (2016) 38:437-42. doi: 10.1097/MPH.0000000000000601

9. Liu L, Oza S, Hogan D, Perin J, Rudan I, Lawn JE, et al. Global, regional, and national causes of child mortality in 2000-13, with projections to inform post2015 priorities: an updated systematic analysis. Lancet. (2015) 385:430-40. doi: 10.1016/S0140-6736(14)61698-6

10. Pena A, Hong A. Advances in the management of anorectal malformations. Am J Surg. (2000) 180:370-6. doi: 10.1016/S0002-9610(00)00 491-8

11. Siddiqui DE, Ashraf MS, Iftikhar S, Belgaumi AF. Predictors of treatment abandonment for patients with pediatric cancer at Indus Children Cancer
Hospital, Karachi, Pakistan. Pediatr Blood Cancer. (2018) 65:e26818. doi: $10.1002 /$ pbc. 26818

12. Tennant PW, Pearce MS, Bythell M, Rankin J. 20-year survival of children born with congenital anomalies: a population-based study. Lancet. (2010) 375:649-56. doi: 10.1016/S0140-6736(09)61922-X

13. Van Lennep M, Singendonk MMJ, Dall'Oglio L, Gottrand F, Krishnan U, Terheggen-Lagro SWJ, et al. Oesophageal atresia. Nat Rev Dis Primers. (2019) 5:26. doi: 10.1038/s41572-019-0077-0

Conflict of Interest: The authors declare that the research was conducted in the absence of any commercial or financial relationships that could be construed as a potential conflict of interest.

Copyright (c) 2020 Yang, Cai, Liao, Peng and Huang. This is an open-access article distributed under the terms of the Creative Commons Attribution License (CC BY). The use, distribution or reproduction in other forums is permitted, provided the original author(s) and the copyright owner(s) are credited and that the original publication in this journal is cited, in accordance with accepted academic practice. No use, distribution or reproduction is permitted which does not comply with these terms. 